\title{
Processos éticos do Conselho Regional de Odontologia do Estado do Pará no período de 2007 a 2010
}

\author{
Ethical law suits from the Regional Council of Dentistry \\ of Pará state from 2007 to 2010
}

\author{
Richardson Bruhmer Jorge Pena ${ }^{1}$, José Henrique dos Santos Corrêa Júnior ${ }^{1}$, Rodolfo \\ José Gomes de Araújo², Leonardo Soriano de Mello Santos ${ }^{3}$, Mário Marques Fernandes ${ }^{4}$, \\ Felippe Bevilacqua Prado ${ }^{5}$, Eduardo Daruge ${ }^{6}$, Eduardo Daruge Junior ${ }^{6}$
}

\begin{abstract}
Pena RBJ, Corrêa Júnior JHS, Araújo RJG, Santos LSM, Fernandes MM, Prado FB, Daruge E, Daruge Junior E. Processos éticos do Conselho Regional de Odontologia do Estado do Pará no período de 2007 a 2010. Saúde, Ética \& Justiça. 2013;18(1):116-23.

RESUMO: Os profissionais da área odontológica estão cada vez mais sujeitos a processos éticos, sendo indiscutível a necessidade de precaução contra possíveis ações instauradas por pacientes e colegas de profissão. O objetivo deste trabalho foi analisar aspectos quantitativos relacionados aos processos éticos junto ao Conselho Regional de Odontologia Secção Pará (CRO-PA) no período de janeiro de 2007 a dezembro de 2010. A análise dos documentos fornecidos pela instituição $(\mathrm{n}=67)$ mostrou que o fator motivador mais frequentemente verificado foi a insatisfação em relação aos resultados obtidos, qualificada como imperícia ou imprudência, com 40,3\%, seguido de irregularidade (26,9\%), propaganda indevida (19,4\%) e constrangimento (7,5\%). Esses dados indicam que a população entende que os maus resultados são decorrentes de falta de preparo técnico dos profissionais no exercício da profissão e que existem dentre os cirurgiões-dentistas uma evidente carência de conhecimentos deontológicos sobre publicidade e propaganda. Estes dados indicam que população entende que os maus resultados são decorrentes de falta de preparo técnico dos profissionais no exercício da profissão e que existe dentre os cirurgiões-dentistas, uma evidente carência de conhecimentos deontológicos sobre publicidade e propaganda.
\end{abstract}

DESCRITORES: Ética odontológica; Códigos de ética; Odontologia legal/ética; Conselhos de especialidade profissional/ética; Conselhos de especialidade profissional/legislação \& jurisprudência; Brasil.

1. Cirurgião-Dentista (ESAMAZ).

2. Cirurgião-Dentista, Mestre em Odontologia (UFPA).

3. Cirurgião-Dentista, Biomédico, Especialista em Cirurgia e Traumatologia Buco Maxilo Faciais pela EAP-APCD Piracicaba, SP; Especialista e Mestre em Odontologia Legal e Deontologia FOP-UNICAMP.

4. Cirurgião-Dentista Especialista e Mestre em Odontologia Legal e Deontologia FOP-UNICAMP.

5. Cirurgião-Dentista. Especialista, Mestre e Doutor em Anatomia FOP-UNICAMP.

6. Cirurgião-Dentista. Especialista, Mestre e Doutor em Odontologia Legal e Deontologia FOP-UNICAMP.

Endereço para correspondência: Leonardo Soriano de Mello Santos. Travessa Almirante Wandenkolk, 1040 - Apto. 1802. Centro

- Belém, PA. CEP: 66.055-030. E-mail: leonardosoriano@hotmail.com 


\section{INTRODUÇÃO}

$\mathbf{S}$ egundo Silva ${ }^{1}$, dentre os temas do momento que mais atingem a classe odontológica estão aqueles relacionados aos processos éticos movidos contra cirurgiões-dentistas (CDs), seja por seus pacientes, por seus funcionários ou, até mesmo, pelos colegas de profissão.

Os profissionais da área odontológica estão cada vez mais sujeitos a estes processos, sendo indiscutível a necessidade de se prepararem melhor na área deontológico-forense para o exercício profissional, de modo a afastar a possibilidade de sofrer processos tanto na área administrativa como na legal ${ }^{2-4}$.

Questões deontológicas relacionadas à prática odontológica ocorrem rotineiramente e podem envolver diversos aspectos subjetivos e objetivos, como aqueles referentes ao paciente, à organização dos serviços de saúde, ou mesmo ao relacionamento com os colegas e com a sociedade como um todo. No entanto, os profissionais nem sempre foram preparados para lidar com conflitos nesta área e, em especial na odontologia, as dificuldades na resolução de tais conflitos são reforçadas pela excessiva tecnificação do trabalho ${ }^{2,5,6}$.

No caso de denúncia ou representação no Conselho Regional de Odontologia (CRO), a mesma é feita por escrito, contendo assinatura e qualificação do denunciante, exposição do fato em suas circunstâncias, além do nome e endereço de testemunhas, se houver. A mesma será analisada pelo presidente e encaminhada à comissão de ética para apuração. Caso a denúncia seja improcedente, será arquivada. Se for constatado algum tipo de infração ética, o presidente da comissão de ética marcará audiência de conciliação e instrução. $\mathrm{O}$ denunciado deverá se apresentar com sua defesa por escrito e munido de advogado, de preferência. Caso não haja acordo entre as partes, o processo será encaminhado para perícia técnica (se for o caso), cujo perito será indicado pelo conselho. O laudo pericial será analisado juntamente com os demais elementos do processo pela comissão de ética, a qual emitirá parecer baseado no Código de Processo Ético Odontológico (CEO) ${ }^{7}$.

Os conselhos possuem "poder e dever" processante e punitivo sobre os inscritos em seus quadros, cumprindo-lhes apurar as denúncias que chegarem ao seu conhecimento, aplicando, após o devido e regular processamento disciplinar, as penalidades previstas, podendo culminar na cassação do direito do exercício profissional ${ }^{2,6,7}$.

A partir disso, o presente estudo teve como objetivo analisar aspectos quantitativos relacionados aos processos éticos junto ao Conselho Regional de Odontologia Secção Pará (CRO-PA) no período de janeiro de 2007 a dezembro de 2010.

\section{MÉTODOS}

A presente pesquisa foi aprovada pelo Comitê de Ética em Pesquisa da Faculdade de Odontologia de Piracicaba da Universidade Estadual de Campinas (CEP-FOP-UNICAMP).

As informações foram obtidas por meio das fichas de coleta de dados dos registros junto aos arquivos do CRO-PA, no período de janeiro de 2007 a dezembro de 2010. Realizou-se análise descritiva para cada uma das variáveis: a) o número de processos, b) os fatores motivadores, c) o gênero prevalente do denunciante e do denunciado, bem como d) a faixa etária dos cirurgiões-dentistas envolvidos. Para a tabulação dos dados, utilizaram-se os

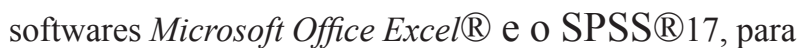
a realização dos gráficos.

Os processos considerados tiveram início no período mencionado, sendo que, no momento da realização da pesquisa, alguns haviam sido encerrados por ausência de provas ou por acordo já cumprido e outros ainda estavam em decurso, seja por cumprimento de acordo ainda em decorrência, seja por motivos de sua transcorrência normal.

Os formulários de coleta de dados foram submetidos à apreciação da plenária do CRO-PA, sendo que os processos foram liberados com a ressalva de que se mantivesse a privacidade dos envolvidos de acordo com a norma da Agência Nacional de Saúde (ANS) 196/96. Os formulários foram preenchidos por apenas um pesquisador, de maneira a eliminar interpretações cruzadas, não havendo necessidade de calibração entre pesquisadores.

\section{RESULTADOS}

A Figura 1 apresenta a distribuição dos processos éticos contra profissionais registrados no CRO-PA, no período de 2007 a 2010. Foi encontrado, para este período, um total de 67 processos $(n=67)$. Pode-se verificar que neste intervalo de tempo, o maior número de reclamações centrou-se no ano de $2009(34,3 \%, \mathrm{n}=23)$, seguido dos anos de 2010, 2008 e 2007 ( $31,3 \%$ ou $n=21,19,4 \%$ ou $n$ $=13$ e $14,9 \%$ ou $n=10$, respectivamente).

Para a variável denunciante, a Figura 2 apresenta sua distribuição nos processos éticos instaurados contra profissionais inscritos no Conselho Regional de Odontologia- PA, no período de 2007 a 2010. Assim observa-se que, $38,8 \%(\mathrm{n}=26)$ dos processos instaurados foram ex-ofício (denúncia anônima ou fruto da fiscalização). Percentual idêntico ao de denúncias realizadas por mulheres. 


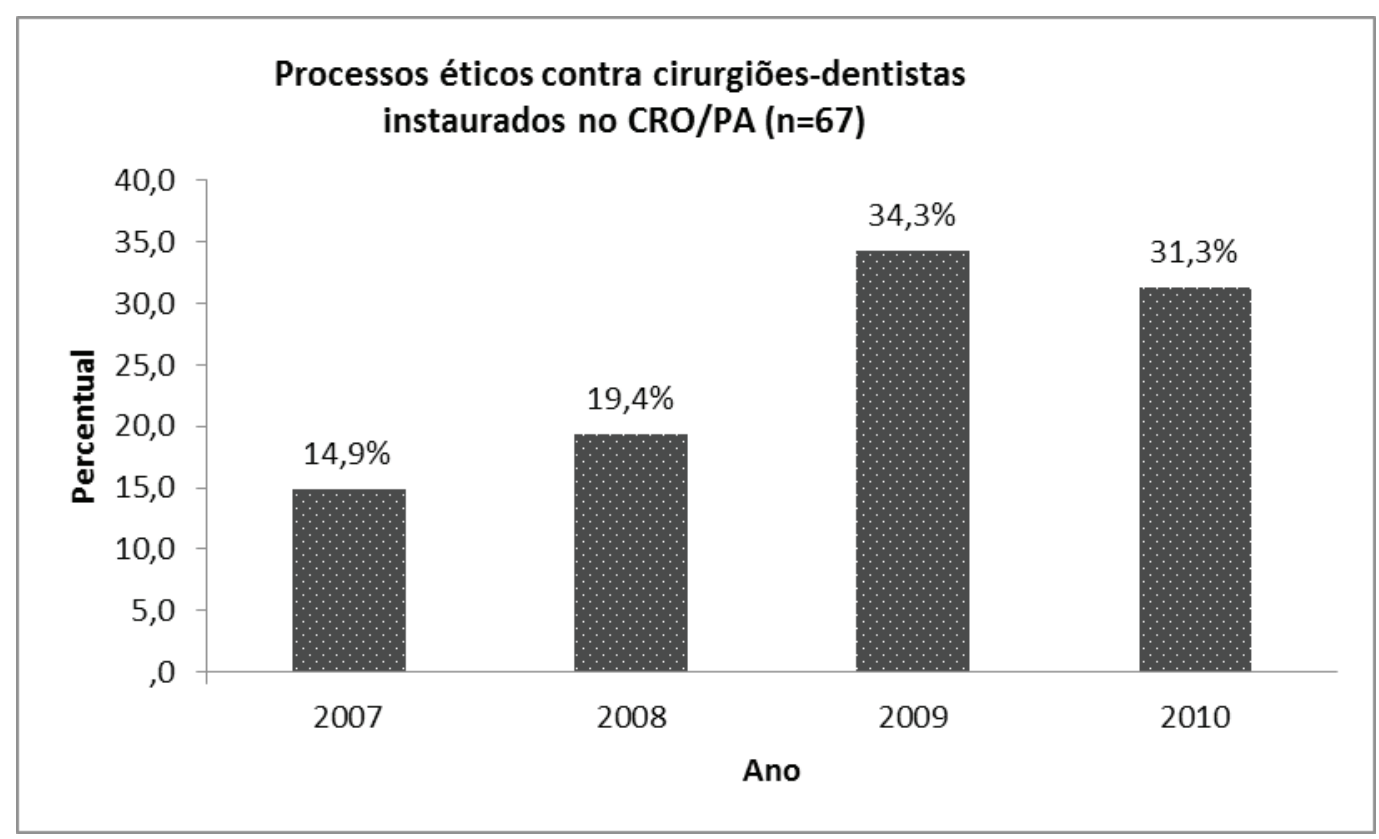

Fonte: Conselho Regional de Odontologia - PA.

Figura 1. Percentuais de processos éticos instaurados no CRO/PA, nos anos de 2007 a 2010

\section{Perfil dos denunciantes nos processos éticos no CRO/PA ( $n=67)$}

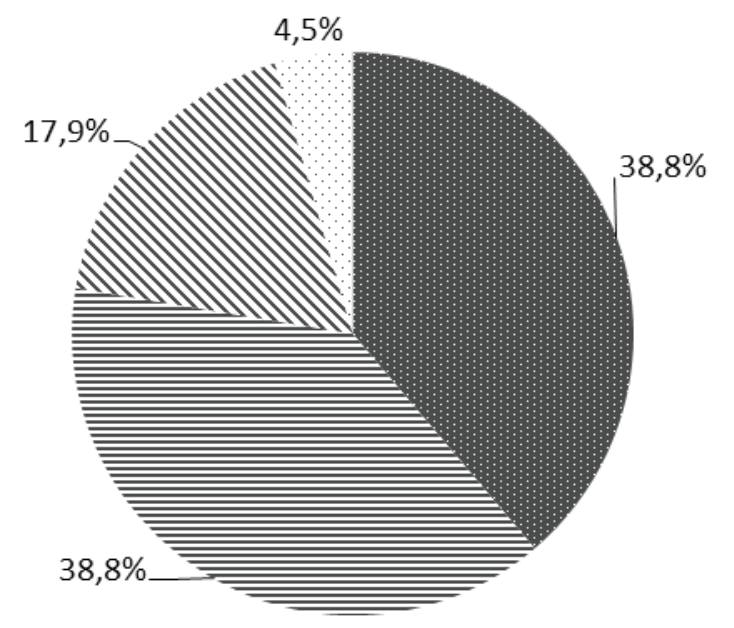

Bx-offício

$\equiv$ Feminino

N Masculino

Pessoa Jurídica

Fonte: Conselho Regional de Odontologia - PA.

Figura 2. Perfil dos denunciantes dos processos éticos instaurados no CRO/PA, no período de 2007 a 2010

A Figura 3 apresenta o perfil quanto ao gênero dos denunciados da amostra. Cinquenta e cinco vírgula dois por cento $(n=37)$ dos profissionais processados eram do sexo masculino e em $6 \%(n=4)$ dos processos a denúncia abrangeu mais de um profissional (tanto homens quanto mulheres). 


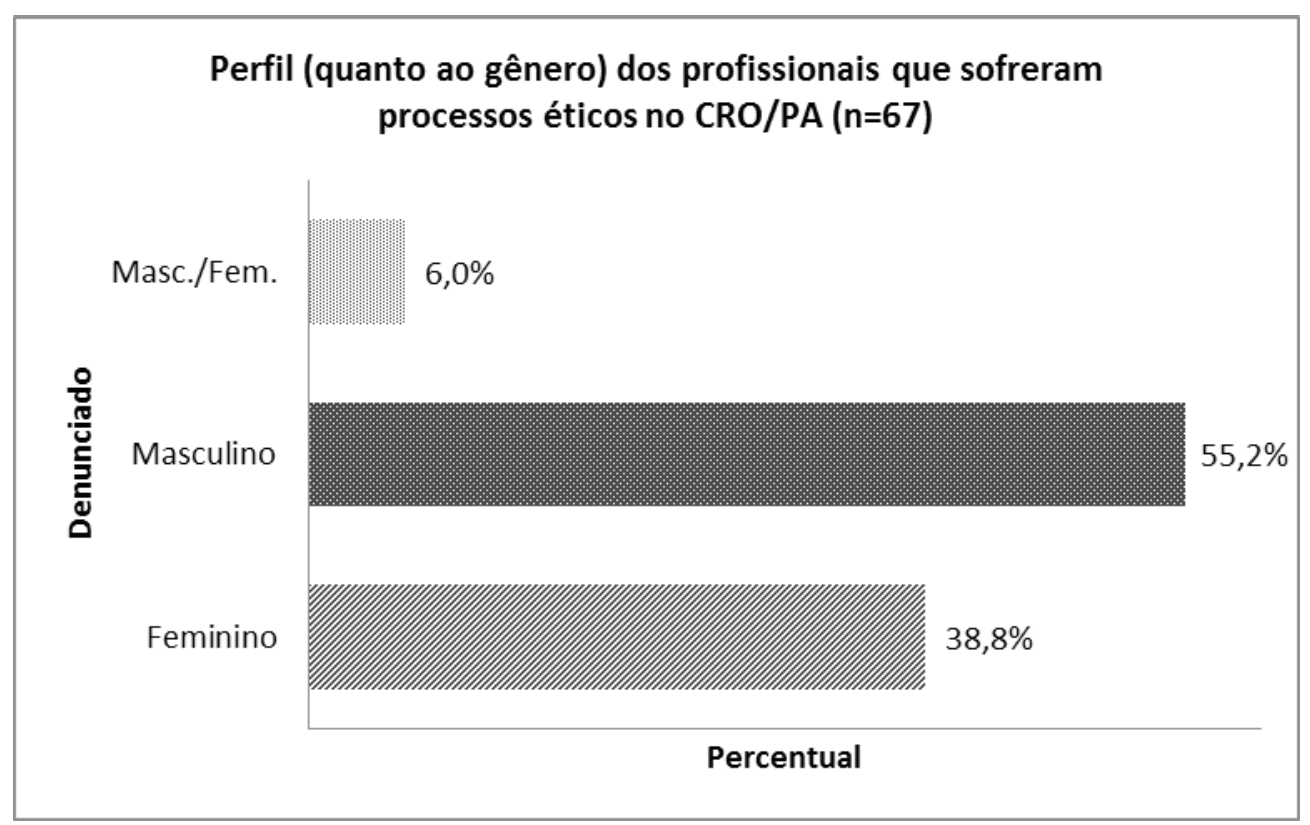

Fonte: Conselho Regional de Odontologia - PA.

Figura 3. Perfil, quanto ao gênero dos profissionais na odontologia, que sofreram processos éticos, instaurados no CRO/ PA, no período de 2007 a 2010

A Figura 4 indica o perfil dos fatores que alegações de imperícia ou imprudência os principais motivaram os processos éticos na amostra, sendo motivos encontrados $(40,3 \%, \mathrm{n}=27)$.

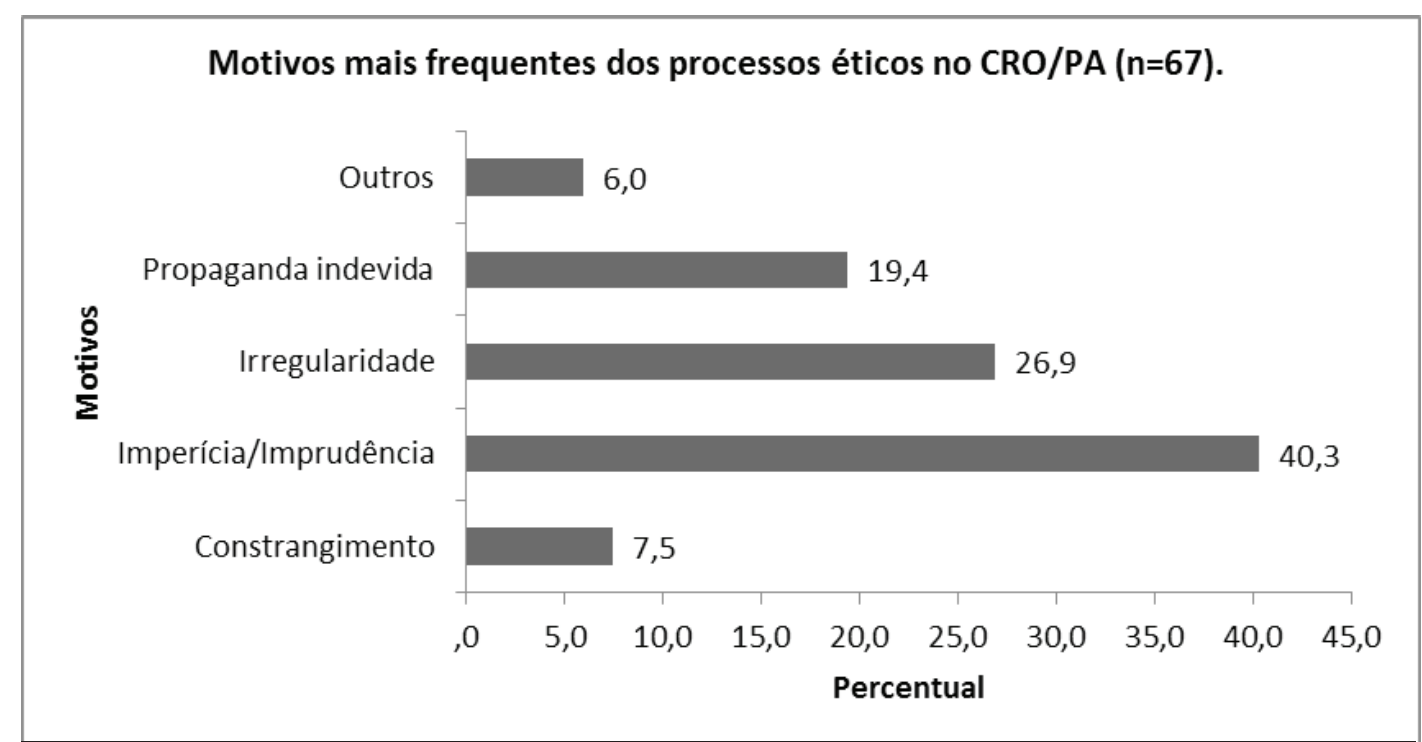

Fonte: Conselho Regional de Odontologia - PA.

Figura 4. Motivos alegados junto ao CRO/PA, no período de 2007 a 2010, para instauração processos éticos (valores em percentual)

Quanto à qualificação profissional, em apenas um caso o denunciado não era cirurgião-dentista, e sim auxiliar de prótese dentária.

A maioria dos casos da amostra foi arquivada $(83,6 \%, \mathrm{n}=56)$, quer por acordo entre as partes, quer pela falta de provas ou ainda pela condenação/ absolvição do denunciado. O restante dos processos ainda estava em andamento ao final de 2010, quando a coleta foi encerrada (Figura 5). 


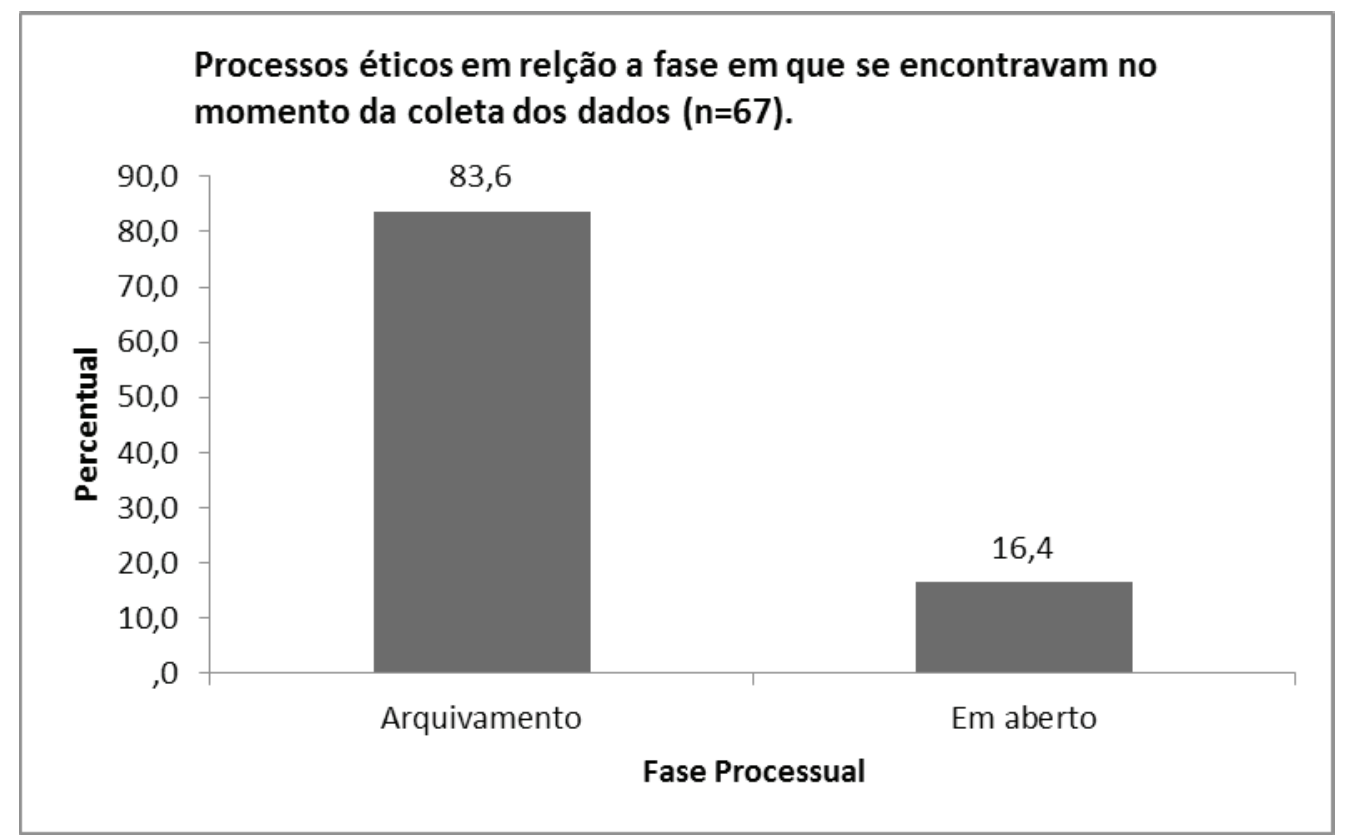

Fonte: Conselho Regional de Odontologia - PA.

Figura 5. Fase processual em que se encontravam os processos éticos no CRO/PA no momento da coleta dos dados

\section{DISCUSSÃO}

Muitas vezes, em função do desconhecimento da sociedade em relação às atribuições dos conselhos regionais de odontologia, queixas relacionadas à responsabilidade civil dos cirurgiões-dentistas são encaminhadas às regionais, entretanto, como não compete às mesmas julgar tais méritos, e, sim, apenas o comportamento ético do $\mathrm{CD}$ durante o exercício profissional, essas reclamações não foram abordadas neste trabalho ${ }^{1,8}$.

Vale salientarque, pelo estabelecido na Lein ${ }^{\circ} 4.324$, que instituiu o $\mathrm{CFO}$ e os CROs, os conselhos regionais de odontologia não têm competência para julgar outros âmbitos que não o deontológico ${ }^{9}$. Outrossim, muitas das queixas frente aos CDs, que não administrativas, acabam por ser encaminhadas a estes órgãos, pela visibilidade que possuem diante da sociedade.

Em um mercado cada vez mais competitivo, com clientes cada vez mais exigentes, os profissionais se adequam aumentando os investimentos em marketing, capacitação, planejamento e relacionamento interpessoal. A necessidade de granjear clientela em função do aumento na competitividade do mercado odontológico, associada ao desconhecimento das normas éticas no que tangem à propaganda e à publicidade, reflete-se no aumento de instruções e processos éticos nos Conselhos Regionais de Odontologia brasileiros ${ }^{2,6}$. Os dados encontrados no presente estudo mostram uma curva crescente em relação ao aumento dos processos, conforme ocorreu no estudo de Oliveira et al. ${ }^{6}$. Franco ${ }^{10}$ que analisaram o número de reclamações no CRO-GO no período de janeiro de 2000 a dezembro de 2005, em que, dos 387 casos denunciados, em 357 houve instauração de processo ético, também suportando a curva processual crescente.

O comportamento do $\mathrm{CD}$ diante da confecção e guarda da documentação profissional pode ser uma das causas deste quadro, pois a grande maioria dos profissionais não tem conhecimento adequado do $\mathrm{CEO}$ e do Código de Ética do Consumidor (CDC), não produzindo documentação profissional adequada ficando, portanto, mais sujeita a ações judiciais ${ }^{6,11-12}$.

O despreparo do $\mathrm{CD}$, em decorrência do pouco conteúdo ensinado sobre Odontologia Legal e ética odontológica, seja na graduação ou em cursos de pósgraduação $0^{11}$, se reflete no aumento das demandas judiciais e reclamações junto aos CROs. Portanto, sugere-se que seria necessária uma reestruturação no ensino da Odontologia Legal no país, viabilizando uma integração entre a teoria e a prática ${ }^{13}$. Na busca pelo posicionamento no mercado de trabalho, o profissional deve sempre manter-se reto com relação à sua conduta profissional, evitando os atalhos da competição desonesta e mercantilista ${ }^{10}$.

Nesse sentido, também publicou o Jornal do $\mathrm{CFO}^{14}$, mostrando que houve aumento significativo do número de processos éticos nos conselhos regionais, relativos principalmente à publicidade ou propaganda 
irregular, da qual demanda a grande maioria dos 4.018 processos instaurados nas 27 regionais do Conselho entre os anos de 2000 e 2004. Esses dados não refletem apenas um aumento repentino na conduta antiética dos profissionais, mas também um aumento da fiscalização por parte dos conselhos e um aumento do número total de profissionais e clínicas registradas no país, acompanhado pelo aumento das denúncias. Como consequência as regionais têm assumido postura educativa, além de implementarem um termo de ajustamento de conduta aos infratores, com o intuito de informar e advertir o profissional antes que sofra eventual processo ético.

No mês de setembro de 2012, 6.358 profissionais encontram-se inscritos no CRO-PA, sendo que 1.947 são do sexo masculino e, a grande maioria, 4.411 são do sexo feminino (Fonte: CRO-PA).Esses dados mostram um aumento no número de profissionais em relação ao apontado por Paranhos et $\mathrm{al}^{3}$. Denota-se que, apesar de serem maioria na regional, as mulheres parecem ser mais cautelosas no que se refere à ética profissional, pois os cirurgiões-dentistas homens foram mais vezes processados em relação às suas colegas.

No período analisado, os fatores motivadores - imperícia/imprudência em $40,3 \%$ dos casos (insatisfação em relação aos resultados obtidos); irregularidades em 26,9\% (ex. inscrição invalida ou clínica sem registro no CRO); propaganda indevida em 19,4\% (participação em sites de compra coletiva, caracterizando mercantilização da profissão ou publicidade de meios de pagamento); constrangimento em 7,5\% (pacientes alegando que, em função da inadequação do tratamento, houve comprometimento de sua autoestima subjetiva e objetiva) e outros fatores em geral em 6\%(falta de comunicação ou custo inesperado) mostraram patamares diferentes para variáveis semelhantes quando comparados com o estudo de Garcia et al. ${ }^{2}$, que verificaram que a publicidade foi mais prevalente entre os fatores motivadores de ações éticas.

Panfletagem, propaganda ou anúncio irregular, considerados propaganda indevida pelo Código de Ética Odontológico ${ }^{15}$, foram a segunda situação mais frequentemente encontrada na amostra $(19,4 \%)$. Nesse sentido cabe lembrar que panfletagem também pode ser considerada crime ambiental segundo a Lei $\mathrm{n}^{\circ} 9605$ de 1998, passível de punição ética, cível e criminal ${ }^{16}$. Nesse sentido também foram os achados de Salibaet al. ${ }^{17}$ que avaliaram as infrações éticas dos CDs no tocante à comunicação, com destaque para as placas odontológicas em São Paulo-SP. Analisaram 70 placas em consultórios de São Paulo e concluíram que apenas $17,1 \%$ eram adequadas.

A questão da propaganda foi protagonista dos motivos de processos éticos no trabalho de Franco ${ }^{10}$, conforme os escores a seguir: panfletagem, propaganda irregular ou anúncio irregular $(61,06 \%)$, queixas de tratamento apresentadas pelo paciente $(12,89 \%)$, queixas relativas a relacionamento $(8,68 \%)$, exercício ilegal da profissão $(8,12 \%)$, acobertamento do exercício ilegal da profissão $(7,84 \%)$ e assédio $(0,28 \%)$. O autor já naquela época deixava claro que se os profissionais conhecessem os aspectos ético-legais da profissão, quase que a totalidade das queixas deixaria de existir.

Quanto ao aspecto relacionamento, a amostra revelou que 11 profissionais foram processados no período abrangido pelo estudo. Entende-se como problema de relacionamento aquele de desavenças ocorridas entre paciente e profissional durante $\mathrm{o}$ tratamento odontológico, capaz de ocasionar desconforto entre as partes e quebra do contrato de prestação de serviços, seja tácita ou formalmente. Nesta modalidade, os acenos verbais praticados pelo profissional acerca do tratamento ou sobre a duração do mesmo, aliados ao pouco esclarecimento fornecido ao paciente, costumam ser os grandes promotores do desgaste da relação ${ }^{8}$.

Com relação aos resultados dos processos éticos instaurados no período analisado, 67 foram julgados. Destes, $56(83,6 \%)$ foram arquivados em função de acordos ou improcedência da denúncia, e 11 estavam em aberto até a conclusão do levantamento de dados deste estudo. Em relação aos acordos, é digno de destaque que neles os denunciados reconhecem a legitimidade da denúncia, ou preferem, a fim de evitar ou extinguir o penoso e desgastante desenrolar do processo ético, acatar as solicitações do reclamante. $\mathrm{O}$ arquivamento se estabelece quando o denunciante se ausenta da audiência, a denúncia é improcedente, ou quando é expressamente solicitado pelas partes?

\section{CONCLUSÕES}

Concluiu-se que não há diferença quanto ao gênero na apresentação da denúncia, que há um maior número de processos contra profissionais homens, as queixas mais frequentes são quanto à imperícia e imprudência (insatisfação em relação aos resultados obtidos) e a maioria dos processos instaurados foram arquivados. 
Pena RBJ, Corrêa Júnior JHS, Araújo RJG, SANTOS LSM, Fernandes MM, Prado FB, Daruge E, Daruge Junior E. Ethical law suits from the Regional Council of Dentistry of Pará state from 2007 to 2010. Saúde, Ética \& Justiça. 2013;18(1):11623.

ABSTRACT: With dental health professionals becoming ever more subject to ethical law suits, there is, without question, a need to safeguard against possible accusations of patients and professional colleagues. In this paper, the authors analyze quantitative aspects related to ethical processes in the Regional Council of Dentistry from Pará, Brazil State (CRO-PA) from January 2007 to December 2010. From The documents provided by CRO-PA ( $n=67)$ it was possible to observe that malpractice and imprudence were the main issues of complaint (related to acquired results) being $40.3 \%$ of the cases, followed by irregularity $(26.9 \%)$, misuse of marketing $(19.4 \%)$ and embarrassment $(7.5 \%)$. These data showed that the general population understands bad treatment as a result of a lack of professional training and that there is a need for a better preparation when marketing and propaganda are in state. The acquired data suggest that the general population understands bad results as a lack of appropriate technical preparation of the dentists and, there is, among these professionals, a need for more knowledge related to ethics in marketing and advertising.

KEYWORDS: Ethics, dental; Codes of ethics; Forensic dentistry/ethics. Specialty boards/ethics; Specialty boards/ legislation \& jurisprudence; Brazil.

\section{REFERÊNCIAS}

1. Silva RHA. Como evitar processos em odontologia parte I. J Odonto. 2007 maio 13 [citado em 02 fev. 2011]. Disponível em: http://www.jornaldosite.com.br/materias/ artigos\&cronicas/anteriores/ricardo $\% 20$ henrique $\% 20$ silva/artigoricardohenrique118.htm

2. Garcia SJ, Caetano JC. O código de ética odontológica e suas infrações: um estudo sobre os processos éticoprofissionais dos cirurgiões dentistas do estado de Santa Catarina. Odontologia. Clin Cientif. 2008;7(4):307-13. Disponível em: http://bases.bireme.br/cgi-bin/wxislind. exe/iah/online/?IsisScript=iah/iah.xis\&src=google\&base $=$ LILACS\&lang $=$ p\&nextAction $=$ lnk\&exprSearch $=5055$ 96\&indexSearch $=$ ID

3. Paranhos LR, Ricci ID, Almeida Filho RP, Castro R, Scananvivi MA. Análise do mercado de trabalho odontológico na região norte do brasil. Rev Odonto. 2009,17(34):27-36. Disponível em: http://www.cidadesp. edu.br/old/revista_odontologia/pdf/maio_agosto_2009/ Unicid_2(2)_2009_104-118.pdf

4. Pontual ML, Devito KL, Almeida SM. A Radiologia a Serviço da Documentação Legal. Revista ABO Nacional. 2006;13(6):369-72.

5. Amorim AG, Souza ECF. Problemas éticos vivenciados por dentistas: dialogando com a bioética para ampliar o olhar sobre o cotidiano da prática profissional. Ciên Saúde Coletiva. 2010;15(3):869-78. DOI: http://dx.doi. org/10.1590/S1413-81232010000300030

6. Oliveira OF, Kairalla SA, Kairalla RA, Torres FC, Paranhos RL. Perfil das denúncias éticas realizadas ao Conselho Regional de Odontologia - uma reflexão. Rev Assoc Paul Cir Dent. 2011;65(2):142-4. Disponível em: http://bases.bireme.br/cgi-bin/wxislind.exe/iah/ online/?IsisScript $=$ iah $/$ iah. xis $\&$ src $=$ google $\&$ base $=$ BBO \&lang $=\mathrm{p} \&$ nextAction $=$ lnk\&exprSearch $=35454 \&$ indexS earch=ID

7. Brasil. Conselho Federal de Odontologia. Código de
Processo Ético Odontológico. Resolução CFO n. 59, de 07 de Outubro de 2004. Dispõe sobre o Código de Processo Ético Odontológico. Rio de Janeiro, RJ; 2004 [citado em 07 jan. 2012]. Disponível em: http://cfo.org. br/wp-content/uploads/2009/09/codigo_proc_etico.pdf

8. Saquy PC, Pécora JD, Silva RG, Souza Neto MD. $O$ código de defesa do consumidor e o cirurgiãodentista. Rev Paul Odontol. 1993;15(4):4-5. Disponível em: http://bases.bireme.br/cgi-bin/wxislind.exe/iah/ online/?IsisScript $=\mathrm{iah} / \mathrm{iah} . x \mathrm{xis} \&$ nextAction $=\operatorname{lnk} \&$ base $=\mathrm{L}$ ILACS\&exprSearch=132839\&indexSearch=ID\&lang $=p$

9. Brasil. Lei 4.324, de 14 de Abril de 1964. Institui o Conselho Federal e os Conselhos Regionais de Odontologia. Diário Oficial da União. 1964 [citado 15 fev. 2012]. Disponível em: http://www.jusbrasil.com.br/ legislacao/128654/lei-4324-64

10. Franco EL. Levantamento dos processos éticos no CROGO no período 2000/2005 [Monografia]. Campinas: FOP- UNICAMP; 2006.

11. Fernandes MM, Bragança DPP, Paranhos LR, Francesquini Júnior L, Daruge E, Daruge Júnior E. Reflexão odontolegal sobre o tempo de guarda da documentação dos pacientes. RFO UPF. 2011;16(1):7-12. Disponível em: http://files.bvs.br/upload/S/1413-4012/2011/v16n1/ a2156.pdf

12. Guerra LM. Responsabilidade civil e criminal nas especialidades odontológicas [Monografia]. Piracicaba: FOP/UNICAMP; 1999.

13. Altafim HC. Modelo de contratos de prestação de serviços odontológicos- Aspectos éticos e legais [Dissertação]. Piracicaba: Faculdade de Odontologia de Piracicaba UNICAMP; 2003.

14. Ajustando condutas, evitando punições. Processos éticos. J CFO. 2005 mai/jun., p. 10.

15. Brasil. Conselho Federal de Odontologia. Resolução CFO 
Pena RBJ et al. Processos éticos do Conselho Regional de Odontologia do Estado do Pará no período de 2007 a 2010.

118, de 11 de maio de 2012. Aprova o Código de Ética Odontológico. Diário Oficial da República Federativa do Brasil. 2012 jun. 14; Seção 1. p.118.

16. Brasil. Lei 9.605, de 12 de Fevereiro de 1998. Dispõe sobre as sanções penais e administrativas derivadas de condutas e atividades lesivas ao meio ambiente e dá outras providências. Diário Oficial da União. 1998 fev. 13 [citado em 08 jan. 2012]. Disponível em: http:// www.ibama.gov.br/fauna/legislacao/lei 9605 98.pdf

17. Saliba CA, Daruge E, Moimaz SAS, Ayres JPS. Aspectos éticos e legais da comunicação odontológica - placas odontológicas. Rev Fac Odontol Lins. 1996;9(2):19-21. Disponível em: http://bases.bireme.br/cgi-bin/wxislind. exe/iah/online/?IsisScript $=$ iah/iah.xis\&src $=$ google \&base $=$ BBO\&lang $=$ p\&nextAction $=$ lnk\&exprSearch $=11683 \& \mathrm{i}$ ndexSearch=ID

Recebido em: 19/07/2012

Aprovado em: 01/07/2013 